\title{
ОСОБЕННОСТИ КЛОНАЛЬНОГО МИКРОРАЗМНОЖЕНИЯ СОРТОВ КЛЕМАТИСА (CLEMATIS L.)
}

\author{
O.E. Khanbabaeva, A.E. Matsnev, V.N. Sorokopudov
}

\section{THE FEATURES OF CLONAL MICROREPRODUCTION OF CLEMATIS VARIETIES (CLEMATIS L.)}

\begin{abstract}
Ханбабаева Ольга Евгеньевна - канд. с.-х. наук, доц. каф. ландшафтной архитектуры Российского государственного аграрного университета - МСХА им. К.А. Тимирязева, г. Москва.

E-mail: hanbabaeva@yandex.ru
\end{abstract}

Мацнева Анна Евгеньевна - мл. науч. сотр. лаб. плодоводства Российского государственного аграрного университета - МСХА им. К.А. Тимирязева, г. Москва. E-mail: macnusha@mail.ru Сорокопудов Владимир Николаевич - д-р с.-х. наук, проф. каф. декоративного садоводства и газоноведения Российского государственного университета - МСХА им. К.А. Тимирязева, г. Москва. E-mail: sorokopud2301@mail.ru

В лаборатории плодоводства ФГБОУ ВО РГАУ-МСХА имени К.А. Тимирязева за последнее время собрана обширная коллекция сортов клематиса (около 30). В течение ряда лет ведутся работы по оптимизации методики черенкования этой культуры. Однако для определенных сортов, представляющих большой интерес при использовании в вертикальном озеленении, черенкование малоэфффективно. В первую очередь из-за низкой способности к укоренению ряда махровых и полумахровых сортов. Во-вторых, период нарезки черенков ограничен по времени. В открытом грунте черенкование возможно проводить только один раз в период массового нарастания молодых, не одревесневших побегов до распускания бутонов. Этот период длится в нашей зоне 23 недели, затем побеги быстро одревесневают. При содержании маточных растений в условиях теплицы в процессе вегетации возможно проводить 3 черенкования за сезон. Но с каждым последующим черенкованием количество черенков снижается, так как цветочные почки закладываются все ниже к основанию куста. Также маточное растение сильно истощается от постоянной срезки побегов год от года. За последние 4 года эксплуатации маточников выход черенков снизился примерно
Khanbabaeva Olga Evgenyevna - Cand. Agr. Sci., Assoc., Chair of Landscape Architecture, Russian State Agrarian University - MAA named after K.A. Timiryazev, Moscow.

E-mail: hanbabaeva@yandex.ru

Matsneva Anna Evgenyevna - Junior Staff Scientist, Lab. of Fruit Growing, Russian State Agrarian University - MAA named after K.A. Timiryazev, Moscow.E-mail: macnusha@mail.ru

Sorokopudov Vladimir Nikolayevich - Dr. Agr. Sci., Prof., Chair of Decorative Gardening and Lawn Science, Russian State Agrarian University MAA named after K.A. Timiryazev, Moscow.

E-mail: sorokopud2301@mail.ru

в 2 раза у немахровых сортов и в 3 раза у махровых. Поэтому маточники, начиная с 57-летнего возраста, необходимо омолаживать, чтобы выход посадочного материала не снижался. Все это делает актуальной разработку метода микроклонального размножения клематисов. Этот метод позволит быстро обновить маточники клематиса, а также оздоровить полученный посадочный материал от вирусов и болезней. В работе изучено 10 сортов клематиса из коллекции плодовой станции. Разработана оптимальная технология микроразмножения, подобрана питательная среда, обогащенная гормонами, позволяющая получить высокий коэфффициент размножения по большинству изучаемых сортов.

Ключевые слова: клематис, сорта, маточники, размножение, черенкование, коэфффициент размножения, in vitro, питательная среда, минеральная основа, ризогенез, адаптация.

In the Laboratory of Fruit Growing, FSBEI HE 'Russian State Autonomous Agricultural Academy named after K.A. Timiryazev' an extensive collection of varieties of clematis (about 30 ) has recently appeared. For a number of years the works on optimization of the technique of cutting this culture have been conducted. However, for certain varie- 
ties which are of great interest for using in vertical gardening, cuttings are ineffective. First of all, it is due to low ability to rooting of a number of terry and semi-double varieties. Secondly, the period of cutting of shanks is limited on time. In open ground, it is possible to carry out cuttings only once during the period of mass growth of young, not lignified shoots before buds' opening. This period lasts in our zone for 2-3 weeks, and then the shoots quickly lignify. Keeping mother plants in a greenhouse during vegetation period it is possible to carry out 3 cuttings during a season. But with each subsequent cutting the number of cuttings decreases, since flower buds are laid lower and lower to the base of the bush. Also mother plant is greatly depleted from constant cutting of shoots and from year to year. Over the past 4 years of operation of mother liquors the yield of cuttings decreased by about 2 times in non-terry varieties and 3 times in terry varieties. Therefore, mother liquors, starting from 5-7 years of age, must be rejuvenated so that the yield of planting material does not lose its properties. All this makes urgent the development of the method of microclonal reproduction of clematis. This method will allow you to update mother liquor of clematis quickly, as well as to heal the resulting planting material from viruses and diseases. 10 varieties of clematis from the collection of the fruit station are studied in the research. Optimal technology of microreproduction has been developed; nutrient medium enriched with hormones has been selected, which allows obtaining high reproduction coefficient for most of studied varieties.
Keywords: clematis, varieties, mother liquors, reproduction, cuttings, reproduction coefficient, in vitro, culture medium, mineral base, rhizogenesis, adaptation.

Введение. Клематис (Clematis Dill, exL., 1753), или Ломонос, очень популярная культура, которая широко используется в вертикальном озеленении и садоводстве. Это многолетняя одревесневающая красивоцветущая лиана, способная достигать в длину нескольких метров. Стебель лазящий. Листья расположены супротивно. Цепляется за опору черешком листа. Цветение обильное и очень продолжительное в середине лета. У клематиса выведено много сортов, наряду с которыми до сих пор очень популярны и видовые растения. Регистрацией новых сортов занимаются в Англии в «Королевском садоводческом обществе» (RHS) [1].

Клематисы светолюбивы, теплолюбивы, влаголюбивы и очень требовательны к плодородию почв. Некоторые популярные сорта в условиях средней полосы нуждаются в легком укрытии и соответствующей обрезке. В основном к таким относятся махровые и крупноцветковые сорта. А большинство мелкоцветковых и видовых на зиму даже не снимают с опоры [1, 2].

В нашей работе изучено 10 сортов из коллекции плодовой станции РГАУ-МСХА имени К.А. Тимирязева (табл. 1). Всего в коллекции 30 сортов. Маточные растения выращивают в зимней остекленной теплице, в грядах, с подвязкой к опоре.

\section{Описание изучаемых сортов клематиса коллекции плодовой станции РГАУ-МСХА имени К.А. Тимирязева}

\begin{tabular}{|l|l|}
\hline $\begin{array}{c}\text { Название, сорт } \\
\text { (сокращ. в работе) }\end{array}$ & \multicolumn{1}{|c|}{ Описание, группа обрезки } \\
\hline \multicolumn{1}{|c|}{1} & \multicolumn{1}{|c|}{2} \\
\hline $\begin{array}{l}\text { Kakio } \\
\text { (K) }\end{array}$ & $\begin{array}{l}\text { Немахровый, крупный цветок, в диаметре 12-16 см. Окраска - розовая, с } \\
\text { белой полосой в центре лепестка. Длина лианы 2,5-3,0 м. Вторая группа } \\
\text { обрезки }\end{array}$ \\
\hline $\begin{array}{l}\text { Blue Light } \\
\text { (BL) }\end{array}$ & $\begin{array}{l}\text { Цветки густомахровые, крупные, в диаметре 11-15 см. Окраска цветка - } \\
\text { светло-лавандовая. Длина лианы 2 м. Вторая группа обрезки }\end{array}$ \\
\hline $\begin{array}{l}\text { Dancing Dorien } \\
\text { (DDOR) }\end{array}$ & $\begin{array}{l}\text { Цветки махровые, 6-8 см в диаметре. Окраска белая, тычинки и пыльники } \\
\text { - кремовые. Длина лианы 1,5-2,0 м. Вторая группа обрезки. Очень зимо- } \\
\text { стойкий сорт }\end{array}$ \\
\hline $\begin{array}{l}\text { Princess Diana } \\
\text { (PRDI) }\end{array}$ & $\begin{array}{l}\text { Цветки мелкие, колокольчатые, 3-5 см в диаметре. Окраска темно-розовая. } \\
\text { Длина лианы 2,5-3,0 м. Третья группа обрезки }\end{array}$ \\
\hline $\begin{array}{l}\text { Purpurea Plena } \\
\text { Elegans } \\
\text { (PPE) }\end{array}$ & $\begin{array}{l}\text { Цветки густомахровые, средние по размеру, в диаметре 3-5 см, малиново- } \\
\text { розовые. Цветение обильное. Длина лианы 3,0-3,5 м. Третья группа обрез- } \\
\text { ки }\end{array}$ \\
\hline
\end{tabular}




\begin{tabular}{|l|l|}
\hline \multicolumn{1}{|c|}{1} & \multicolumn{1}{|c|}{ Окончание табл. 1} \\
\hline $\begin{array}{l}\text { Julka } \\
\text { (JL) }\end{array}$ & $\begin{array}{l}\text { Цветок простой, очень крупный, в диаметре до 14 см. Окраска цветка - } \\
\text { темно-фиолетовая с бордовой полосой в центре. Тычинки белые. Длина } \\
\text { лианы до 2 м. Вторая группа обрезки }\end{array}$ \\
\hline $\begin{array}{l}\text { Proteus } \\
\text { (PR) }\end{array}$ & $\begin{array}{l}\text { Цветки крупные, до 18 см в диаметре, простые и полумахровые. Края ле- } \\
\text { пестков волнистые. Окраска от бледно- до темно-сриолетовой. Длина лиа- } \\
\text { ны до 2,5 м. Третья группа обрезки. Сорт практически не поражается гриб- } \\
\text { ными заболеваниями }\end{array}$ \\
\hline $\begin{array}{l}\text { Polish Spirit } \\
\text { (PS) }\end{array}$ & $\begin{array}{l}\text { Цветок простой, крупный, в диаметре до 10 см. Окраска цветка темно- } \\
\text { фиолетовая. Длина лианы 2,5-3,0 м. Третья группа обрезки }\end{array}$ \\
\hline $\begin{array}{l}\text { Innocent Blush } \\
\text { (IB) }\end{array}$ & $\begin{array}{l}\text { Цветки на прошлогодних побегах махровые от светло-розовых до темно- } \\
\text { розовых. Цветки на побегах текущего года простые, до 12 см в диаметре. } \\
\text { Пыльники ярко-желтые. Длина лианы до 2 м. Вторая группа обрезки }\end{array}$ \\
\hline $\begin{array}{l}\text { Daniel Deronda } \\
\text { (DDER) }\end{array}$ & $\begin{array}{l}\text { Цветки крупные, до 12 см, простые, на побегах прошлого года полумахро- } \\
\text { вые. Окраска голубовато-фиолетовая. Пыльники кремовые. Длина лианы } \\
2,0-2,5 \text { м. Первая группа обрезки }\end{array}$ \\
\hline
\end{tabular}

На одном месте в условиях открытого грунта клематис растет до 30 лет, в защищенном грунте маточные растения клематиса требуется омолаживать через 5-10 лет, в связи с тем, что существенно снижается выход зеленых черенков С маточных растений [3].

В связи с возрастающим спросом на посадочный материал сортов клематиса становится актуальным применение новых инновационных технологий ускоренного размножения $[4,5]$.

Метод клонального микроразмножения позволяет быстро обновить маточники клематиса, получить большое количество посадочного материала, а также оздоровить полученный посадочный материал от вирусов и болезней [6].

Цель работы. Совершенствование методики размножения in vitro клематиса в соответствии с требованиями конкретных сортов.

На первом этапе работы стояли следующие задачи: введение в культуру 10 сортов клематиса; использование двух вариантов питательных сред на этапе собственно микроразмножения для изучаемых сортов.

Материалы и методы. В эксперименте использовали 10 сортов клематиса, характеризующихся разной способностью к укоренению in vivo. В качестве эксплантов брали конус нарастания (апекс) с листовыми примордиями, взятыми с молодых нарастающих побегов. Забор верхушек осуществлялся в июне.
Верхушки побегов сначала промывали 15 минут под проточной водой с добавлением поверхностно-активных веществ, потом погружались в 70\%-й спирт на 2-3 секунды, далее проводили стерилизацию с помощью 3\%-го гипохлорита натрия в течение 10 минут. Промытые дистиллированной стерилизованной водой апексы помещали на искусственную питательную среду в условиях ламинар-бокса. Питательную среду автоклавировали при $118^{\circ} \mathrm{C} 18$ минут и разливали в условиях ламинар-бокса в пробирки объемом 10 мл. Культуры инкубировали в световой комнате при интенсивности света 2000 люкс, температуре $24{ }^{\circ} \mathrm{C}$ и 16часовом фотопериоде.

На этапе введения использовали питательную среду MS (Murashige, Skoog, 1962), содержащую микро- и макросоли, витамины (мг/л): тиамин, пиридоксин, никотиновая кислота - по 0,5; инозитол - 100; глицин - 2; сахароза 30000; бакто-агар - 7000 с добавлением гормона БАП (0,4 мг/л) и ИМК (0,05 мг/л).

На этапе размножения среду разливали в стеклянные банки с объемом среды 30 мл. Все сорта высаживали на два типа питательных сред.

1. Питательная среда на основе минеральных солей QL (Quoirin \& Lepoivre, 1977), содержащая следующие вещества (мг/л): витамины тиамин, пиридоксин, никотиновая кислота 
- по 0,5; инозитол - 100; глицин - 2; сахароза 30000; бакто-агар - 7000 с добавлением гормона БАП (0,4 мг/л) и ИМК (0,05 мг/л).

2. Питательная среда на основе минеральных солей MS (Murashige, Skoog, 1962), содержащая следующие вещества(мг/л): витамины тиамин, пиридоксин, никотиновая кислота - по 0,5; инозитол - 100; глицин - 2; сахароза 30000; бакто-агар - 7000 с добавлением гормона БАП (0,4 мг/л) и ИМК (0,05мг/л).

Концентрация гормона БАП (0,4 мг/л) и ИМК (0,05 мг/л) была выбрана на основе ранее сделанных исследований.
В ходе эксперимента учитывали следующие показатели: коэффицциент размножения (суммарное количество одноузловых черенков с одного конгломерата), высоту микропобегов.

Результаты и их обсуждение. Исследования показали, что реакция сортов на условия in vitro зависела от генотипа сорта и состава питательной среды. Инициация длилась 2 месяца, темпы роста и тип размножения зависели от сорта. На этапе введения из 10 сортов ввели 10. Контаминация, или зараженность среды грибными инфекциями, - важный показатель, характеризующий количество прижившихся апексов (рис.).

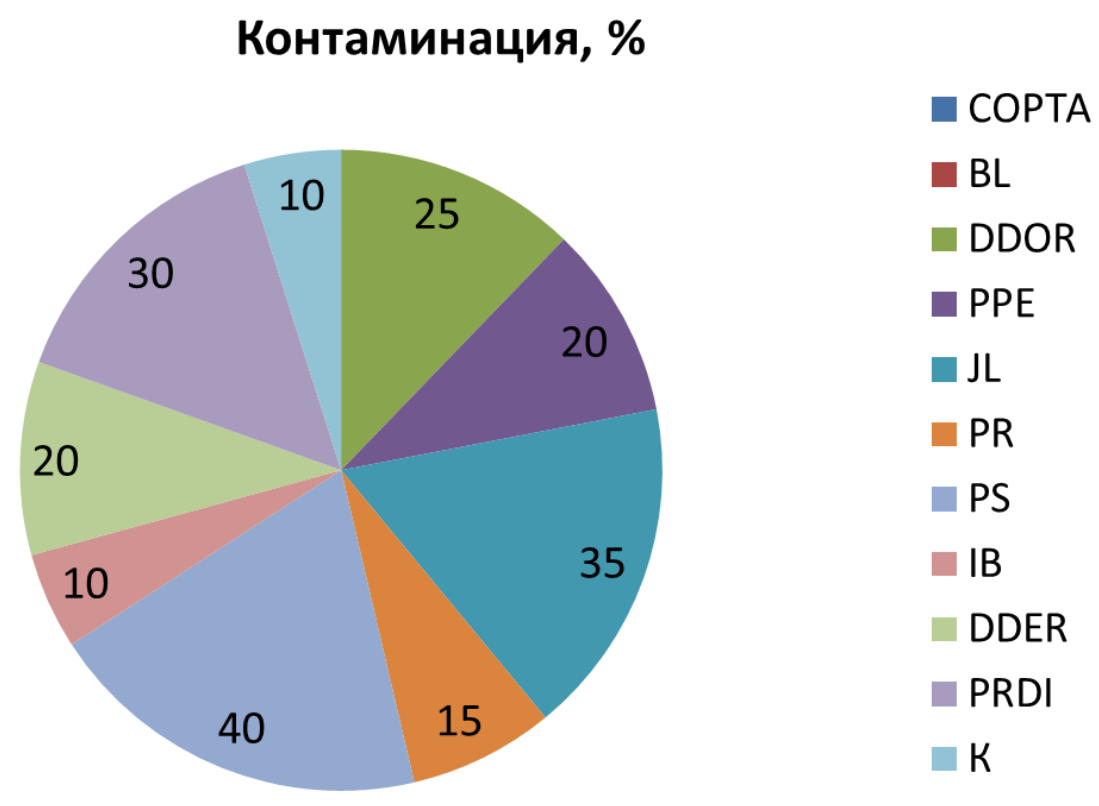

Oпределение контаминации (зараженности) питательной среды на этапе введения в пробирках, \%

Лучшей приживаемостью (80-100 \%) отличались апексы сортов Blue Light, Kakio, Dancing Dorien, Princess Diana, Purpurea Plena Elegans, Proteus, Innocent Blush, Daniel Deronda. Самой низкой контаминацией характеризуются сорта Polisch Spirit (40\%), Julka (35\%), Princess Diana (30\%), соответственно выход прижившихся апексов у них невысокий.
В опыте наблюдали прямую зависимость приживаемости апексов от их размера. С увеличением размера экспланта увеличивалась их способность к регенерации. У эксплантов, взятых с верхушек донорных растений, отмечали интенсивный рост, в то же время использование боковых побегов в качестве исходного материала для выделения эксплантов приводило к задержке роста и развития стерильных культур. 
Коэффицциент размножения на этапе введения в пробирках

\begin{tabular}{|l|c|c|c|c|}
\hline \multicolumn{1}{|c|}{ Сорт } & Длина побегов, см & $\begin{array}{c}\text { Кол-во побегов на } \\
\text { эксплант, шт. }\end{array}$ & $\begin{array}{c}\text { Длина междоузлй, } \\
\text { см }\end{array}$ & $\begin{array}{c}\text { Коэффициент } \\
\text { размножения }\end{array}$ \\
\hline Kakio & 2,1 & 1,2 & 0,5 & 5,0 \\
\hline Blue Light & 2,7 & 1,6 & 0,5 & 6,4 \\
\hline Dancing Dorien & 0,5 & 1,1 & 0,3 & 1,8 \\
\hline Princess Diana & 3,1 & 1,3 & 0,9 & 4,5 \\
\hline $\begin{array}{l}\text { Purpurea Plena } \\
\text { Elegans }\end{array}$ & 4,8 & 1,4 & 0,5 & 7,8 \\
\hline Julka & 1,1 & 1,2 & 0,3 & 4,4 \\
\hline Proteus & 0,9 & 1,1 & 0,4 & 2,5 \\
\hline Polish Spirit & 2,0 & 1,5 & 0,7 & 4,2 \\
\hline Innocent Blush & 1,6 & 1,1 & 0,4 & 4,4 \\
\hline Daniel Deronda & 1,9 & 1,6 & 0,5 & 6,1 \\
\hline HCP 05 & 0,1 & 0,2 & 0,1 & 0,6 \\
\hline
\end{tabular}

По результатам статистической обработки данных можно сделать вывод, что различия сортов по изучаемым показателям достоверны, за исключением случаев, когда у сортов разница по показателям меньше, чем значение НСР 05 [7].

Инициация культур длилась 2-3 месяца в зависимости от сорта. За это время у части сортов на первичных эксплантах сфрормировались одиночные побеги. Снятие апикального доминирования при применении гормона 6-БАП было неполным. Побеги сохраняли способность к дальнейшему нарастанию верхушкой. При этом в пазухах листьев из боковых почек формирова- лись боковые побеги второго порядка. При дальнейшем размножении эти побеги могли использоваться в качестве отдельных субъединиц, что значительно увеличивало коэффрициент размножения. По сумме показателей лучшим был сорт Purpurea Plena Elegans: коэфффициент размножения составил 7,8. Самые низкие показатели продемонстрировали сорта Dancing Dorien и Proteus: коэффицциент размножения соответственно 1,8 и 2,5. Далее проводили сравнение коэфффициента размножения на двух минеральных питательных средах (табл. 3).

Таблица 3

\section{Сравнительный анализ сортов клематиса на стадии размножения на двух средах}

\begin{tabular}{|c|c|c|c|c|}
\hline \multicolumn{1}{|c|}{ Сорт } & Среда & $\begin{array}{c}\text { Средняя длина } \\
\text { побегов, см }\end{array}$ & $\begin{array}{c}\text { Кол-во побегов } \\
\text { на эксплант, шт }\end{array}$ & $\begin{array}{c}\text { Коэффициент } \\
\text { размножения }\end{array}$ \\
\hline \multirow{2}{*}{1} & 2 & 3 & 4 & 5 \\
\hline \multirow{2}{*}{ Kakio } & $\mathrm{MS}$ & 2,3 & 1,4 & 4,2 \\
\cline { 2 - 5 } & $\mathrm{QL}$ & 2,5 & 1,3 & 4,3 \\
\hline \multirow{2}{*}{ Dancing Light } & $\mathrm{MS}$ & 1,5 & 1,2 & 3,4 \\
\cline { 2 - 5 } & $\mathrm{QL}$ & 1,2 & 1,2 & 1,9 \\
\hline \multirow{2}{*}{ P.P. Elegans } & $\mathrm{MS}$ & 2,2 & 1,6 & 3,5 \\
\cline { 2 - 5 } & $\mathrm{QL}$ & 2,6 & 1,6 & 2,2 \\
\hline \multirow{2}{*}{ Julka } & $\mathrm{MS}$ & 4,5 & 1,3 & 5,6 \\
\cline { 2 - 5 } & $\mathrm{QL}$ & 5,3 & 1,2 & 6,8 \\
\cline { 2 - 5 } & $\mathrm{MS}$ & 2,4 & 1,6 & 4,1 \\
\hline
\end{tabular}




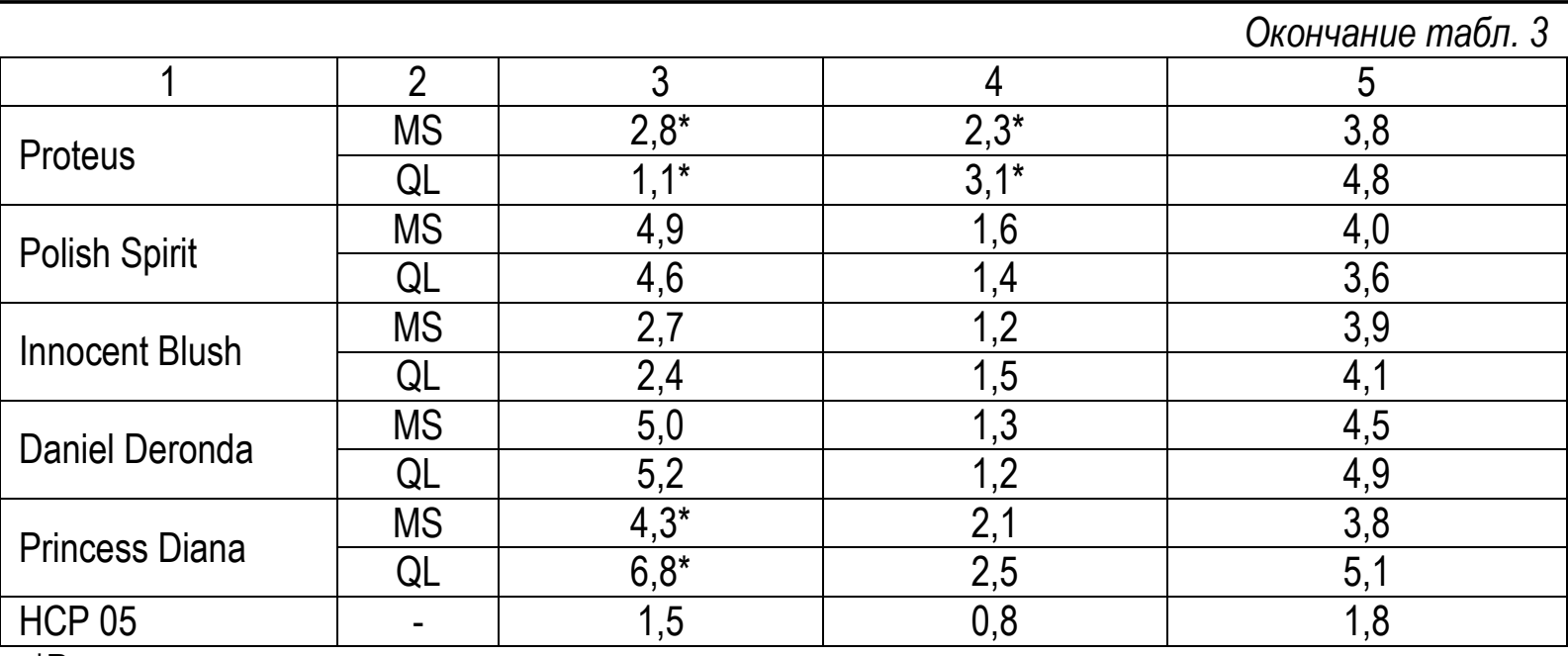

*Различия сред достоверны.

По полученным данным можно сделать вывод, что для большинства сортов с успехом можно применять обе изучаемые среды. Исключение составляют сорта Princess Diana и Proteus, для которых оптимальна среда QL. Исследования показали, что на среде MS лучше развивались сорта Purpurea Plena Elegans $и$ Daniel Deronda, коэффрициент размножения 5,6 и 4,5 соответственно. Коэффиициент размножения в среднем по этим сортам составлял 1:5,5. Высокий коэффициент размножения на среде QL отмечен у сорта Purpurea Plena Elegans - 6,8 и у сорта Princess Diana - 5,1. Влияние минеральной основы питательной среды на коэфрфициент размножения остальных сортов было слабо выражено.

Выводы. Лучшей приживаемостью (80-100%) отличались сорта Blue Light, Kakio, Dancing Dorien, Princess Diana, Purpurea Plena Elegans, Proteus, Innocent Blush, Daniel Deronda. Самой низкой контаминацией характеризуются сорта Polisch Spirit (40\%), Julka (35\%), Princess Diana (30 \%). В опыте наблюдали прямую зависимость приживаемости апексов от их размера. С увеличением размера экспланта увеличивалась их способность к регенерации.

Обе изучаемые минеральные среды не отличались по большинству сортов по коэфффициенту размножения. Поэтому для этапа размножения сортов клематиса рекомендуется среда на основе минеральных солей QL (Quoirin \& Lepoivre, 1977), содержащая следующие вещества (мг/л): витамины тиамин, пиридоксин, никотиновая кислота - по 0,5; инозитол - 100; глицин - 2; сахароза - 30000; бакто-агар - 7000 c добавлением гормона БАП (0,4 мг/л) и ИМК
(0,05 мг/л), и питательная среда на основе минеральных солей MS (Murashige, Skoog, 1962), содержащая следующие вещества (мг/л): витамины тиамин, пиридоксин, никотиновая кислота - по 0,5; инозитол - 100; глицин - 2; сахароза 30000; бакто-агар - 7000 с добавлением гормона БАП (0,4 мг/л) и ИМК (0,05 мг/л).

На этапе размножения следует выделить сорт Purpurea Plena Elegans, коэфффициент размножения которого составил 7,8. Самые низкие показатели продемонстрировали сорта Dancing Dorien и Proteus: коэфффициент размножения соответственно 1,8 и 2,5.

В ходе исследования было выявлено, что реакция сортов на условия in vitro на стадии собственно микроразмножения зависела от генотипа и состава питательной среды. Проведенные исследования показали, что оптимизация условий размножения клематисов in vitro в соответствии с особенностями роста и развития конкретного сорта может повысить эффрективность микроразмножения.

\section{Литература}

1. Соколова Т.А., Бочкова И.Ю. Декоративное растениеводство. Цветоводство: учеб. для студ. вузов. - 4-е изд., стер. - М.: Академия, 2010. - 432 c.

2. Иванова И.В., Ханбабаева О.Е. Декоративное садоводство с основами ландшафтного проектирования. - М.: Изд-во РГАУ-МСХА, 2013. - Ч. 2. - C. 179.

3. Ханбабаева O.E. Размножение декоративных растений: мультемидийное учеб. пособие. - Номер свидетельства RU 201320650, 
РГАУ-МСХА имени К.А. Тимирязева. - М., 2013. - Версия СУБД: Power Point. Объем: 48,8 Мб.

4. Калашникова Е.А., Родин А.Р. Получение посадочного материала древесных, цветочных и травянистых растений с использованием методов биотехнологии: учеб. пособие. - 3-е изд. - М.: МГУЛ, 2004. - 84 с.

5. Коротков О.И., Короткова О.О., Миронова О.Ю. Клематисы в культуре in vitro // Физиологические и молекулярно-генетические аспекты сохранения биоразнообразия и рационального использования растительных ресурсов: мат-лы Междунар. науч. конф. - М., 2005. - С. 221-224.

6. Мазаева А.С., Ковалева И.С., Мацнева А.Е. [и др.]. Инициация стерильных культур фрлокса метельчатого (Plox paniculata L.) // Мат-лы Междунар. науч. конф. - 2018. C. 24-27.

7. Смиряев А.В., Кильчевский А.В. Генетика популяций и количественных признаков. М.: КолосС, 2007. - 272 с.

\section{Literatura}

1. Sokolova T.A., Bochkova I.Yu. Dekorativnoe rastenievodstvo. Cvetovodstvo: ucheb. dlya stud. vuzov. - 4-e izd., ster. - M.: Akademiya, 2010. - $432 \mathrm{~s}$.
2. Ivanova I.V., Hanbabaeva O.E. Dekorativnoe sadovodstvo $S$ osnovami landshaftnogo proektirovaniya. - M.: Izd-vo RGAU-MSKHA, 2013. - Ch. 2. - S. 179.

3. Hanbabaeva O.E. Razmnozhenie dekorativnyh rastenij: mul'temidijnoe ucheb. posobie. - Nomer svidetel'stva RU 201320650, RGAU-MSKHA imeni K.A. Timiryazeva. - M., 2013. - Versiya SUBD: Power Point. Ob"em: 48,8 Mb.

4. Kalashnikova E.A., Rodin A.R. Poluchenie posadochnogo materiala drevesnyh, cvetochnyh i travyanistyh rastenij $\mathrm{s}$ ispol'zovaniem metodov biotekhnologii: ucheb. posobie. - 3-e izd. - M.: MGUL, 2004. - $84 \mathrm{~s}$.

5. Korotkov O.I., Korotkova O.O., Mironova O.Yu. Klematisy $v$ kul'ture in vitro // Fiziologicheskie i molekulyarno-geneticheskie aspekty sohraneniya bioraznoobraziya i racional'nogo ispol'zovaniya rastitel'nyh resursov: mat-ly Mezhdunar. nauch. konf. M., 2005. - S. 221-224.

6. Mazaeva A.S., Kovaleva I.S., Macneva A.E. [i dr.]. Iniciaciya steril'nyh kul'tur floksa metel'chatogo (Plox paniculata L.) // Mat-ly Mezhdunar. nauch. konf. - 2018. - S. 24-27.

7. Smiryaev A.V., Kil'chevskij A.V. Genetika populyacij i kolichestvennyh priznakov. - M.: KolosS, 2007. - 272 s. 